\author{
ARTIGO \\ do $\underline{\text { https://doi.org/10.22481/praxisedu.v16i40.5182 }}$
}

\title{
PROGRAMA PAULISTA LER E ESCREVER E O TRABALHO DOCENTE: ENTRE ORIENTAÇÕES E PADRONIZAÇÕES
}

\author{
THE SÃO PAULO READ AND WRITE PROGRAM AND TEACHING WORK: \\ BETWEEN GUIDELINES AND STANDARDIZATIONS
}

\section{EL PROGRAMA PAULISTA LEER Y ESCRIBIR Y EL TRABAJO DOCENTE: ENTRE ORIENTACIONES Y PADRONIZACIONES}

\author{
Letícia Laís da Silva \\ Universidade Federal de São Carlos - Brasil \\ Géssica Priscila Ramos \\ Universidade Federal de São Carlos - Brasil
}

Resumo: Este artigo teve como por objetivo geral identificar a concepção de docente presente no Programa Ler e Escrever, expondo algumas implicações dessa política para o trabalho do professor. A partir de pesquisa bibliográfica e documental, verificou-se que as orientações e prescrições dadas aos docentes nos escritos dos documentos encaminham para a padronização do trabalho do professor, restringindo-o a instruções, dicas, sugestões, orientações. Seu trabalho é subestimado e sua função é reduzida à colaborador do material, tornando o Programa o centro do processo educacional, e o professor, coadjuvante.

Palavras-chaves: Política educacional paulista; Programa ler e escrever; Trabalho docente.

\begin{abstract}
The purpose of this article was to identify the teachers conception in the Read and Write Program, exposing some implications for teaching work. From a bibliographical and documentary research, it was verified that the guidelines and prescriptions given to the teachers in the documents lead to the standardization of the teacher's work, restricting it to instructions, tips, suggestions, guidelines. His work is underestimated and his function is reduced to material developer, made the Program the center of the educational process, and the teacher, supporting.
\end{abstract}

Keywords: São Paulo's educational politics; Read and write program; Teaching work.

Resumen: Este artículo tuvo como objetivo general identificar la concepción de docente presente en el Programa Leer y Escribir, exponiendo algunas implicaciones de esa política para el trabajo docente. A partir de investigación bibliográfica y documental, se verificó que las orientaciones y prescripciones dadas a los docentes en los escritos de los documentos encaminan para la estandarización del trabajo del profesor, restringiéndolo a instrucciones, sugerencias, orientaciones. Su trabajo es subestimado y su 
función es reducida al colaborador del material, tornado el Programa el centro del proceso educativo, y el profesor, coadyuvante.

Palabras claves: Política educativa paulista; Programa de lectura y escritura; Trabajo docente.

\section{Introdução}

O Programa Ler e Escrever é uma política educacional desenvolvida, em São Paulo, para alunos do ciclo I do ensino fundamental, com várias ações voltadas para o desenvolvimento do ensino e da aprendizagem de suas competências orais e escritas.

Sua história pode ser dividida em três fases centrais. A primeira ocorreu com sua implantação nas escolas municipais da cidade de São Paulo, em 2006, por meio da Portaria 6.328, de 26 de setembro de 2005, durante a gestão de José Serra na prefeitura paulista. Ele foi criado e instituído como Programa "Ler e Escrever - prioridade na Escola Municipal", objetivando desenvolver projetos voltados para reverter "o quadro de fracasso escolar ocasionado pelo analfabetismo e pela alfabetização precária dos alunos do Ensino Fundamental e Médio da Rede Municipal de Ensino" (SÃO PAULO, 2005, p. 1).

O Programa compunha-se, então, do Projeto intitulado "Toda força ao $1^{\circ}$ ano do Ciclo I", do "Projeto Intensivo no Ciclo I - PIC" e do Projeto "Ler e Escrever em todas as áreas do Ciclo II" (SÃO PAULO, 2005). O projeto "Toda força ao $1^{\circ}$ ano do Ciclo I" foi elaborado com vistas a criar "condições adequadas para garantir a aprendizagem da leitura e da escrita a todos os alunos ao final do primeiro ano do Ciclo I" (SÃO PAULO, 2005, p. 4), sob a justificativa de que os estudantes que chegavam ao final do primeiro ano alfabetizados tinham mais chances de sucesso nos anos posteriores. O "Projeto Intensivo no Ciclo I - PIC" foi uma ação focada nos $4^{\circ}$ anos do ensino fundamental e almejava "reverter o quadro" de "fracasso escolar dos alunos nesta etapa da escolarização" (SÃO PAULO, 2005, p. 6). Suas estratégias voltavam-se para dar a oportunidade ao aluno do $4^{\circ}$ ano, que estava em descompasso de aprendizagem com os demais estudantes de seu ano, "melhorar a sua relação com o processo de ensino e de aprendizagem, apropriando-se dos conteúdos básicos desse Ciclo" para ter condições de continuar aprendendo durante o ciclo II (SÃO PAULO, 2005, p. 7). Já o projeto "Ler e Escrever em todas as áreas do Ciclo II" (SÃO PAULO, 2005, p. 9) foi criado para auxiliar o Coordenador Pedagógico a construir um currículo para o ciclo II que envolvesse práticas de leitura e escrita, comprometendo os professores de todas as áreas nesse trabalho. 
A partir dessa experiência e com o início da gestão de José Serra no governo do estado de São Paulo, em 2007, o Programa entrou em sua segunda fase. Assim, a Secretaria de Estado da Educação ampliou o Programa para todas as escolas da região metropolitana da grande São Paulo, em 2008, objetivando "melhorar as condições de ensino e garantir a plena alfabetização até oito anos de idade" (VILLASLOBOS, 2014, p. 25). Com isso, todas as ações iniciadas em 2005 e instauradas na rede municipal de ensino paulistana em 2006 foram estendidas no ano de 2008 para essa região.

Essa ampliação ocorreu por meio da Resolução n. 86, de 19 de dezembro de 2007 (SÃO PAULO, 2007a), que instituiu a implementação do Programa Ler e Escrever, em 2008, no ciclo I do ensino fundamental das escolas estaduais da região metropolitana da grande São Paulo (SÃO PAULO, 2007a). Segundo o art. $1^{\circ}$ da referida Resolução, o Programa tinha o objetivo de alfabetizar todos os alunos de até oito anos de idade com data máxima de 2010 e recuperar a aprendizagem de leitura e escrita dos alunos do ciclo I do ensino fundamental (SÃO PAULO, 2007a, art. $1^{\circ}$ ).

Posteriormente a essa fase, o Programa entrou em um terceiro momento, quando foi ampliado também para as escolas de ensino fundamental do interior paulista, por meio da Resolução n. 96, de 23 de dezembro de 2008 (SÃO PAULO, 2008c), que o estendeu a toda rede de ensino estadual. Segundo o art. $2^{\circ}$ da referida Resolução, a implementação do Programa no interior paulista deveria obedecer às normas e orientações previstas na Resolução n. 86 criada ainda em 2007 (SÃO PAULO, 2008c).

Todavia, é relevante mencionar que as ideias que embasaram a formulação do Programa na Secretaria de Estado da Educação, de algum modo, já estavam sendo gestadas em governos paulistas anteriores quando, sob a legenda do Partido da Social Democracia Brasileira (PSDB) -, desde 1995, detectavam o fracasso escolar na rede de ensino paulista - acompanhado de significativos índices de alunos não alfabetizados, reprovados ou evadidos -, identificando, segundo Ramos (2012; 2013), o professor e sua formação como aspecto central nesse sentido. Podem ser destacadas nessa história a criação do Programa de Educação Continuada (PEC), em 1997, e do Programa de Educação Continuada - Universitário, em 2001, tendo este último o objetivo de possibilitar a formação em nível superior dos docentes em atividade; o Programa Letra e Vida, em 2001, com foco em oferecer capacitação docente sobre o processo de alfabetização; o Rede do Saber, em 2001, com vistas a atuar na formação em nível superior dos professores efetivos da $1^{\mathrm{a}}$ a $4^{\mathrm{a}}$ série que ainda não a tinham e na formação continuada dos profissionais a partir do uso de recursos tecnológicos; o Teia do Saber, criado em 2003, que 
aliava fundamentação teórica e vivências na capacitação docente para atualização em novas metodologias de ensino; dentre outras. Tais ações agiam no sentido de focar o docente com o pressuposto de ser ele o agente central responsável pelos resultados educacionais (RAMOS, 2013), atuando em sua formação inicial e continuada.

Dessa forma, o Programa Ler e Escrever tornou-se, na história da educação paulista, uma das ferramentas centrais focadas em agir sobre o processo formativo e a atuação profissional docente notadamente no que diz respeito à alfabetização.

Com base nesse contexto e em pesquisa bibliográfica e documental, o objetivo deste artigo é identificar a concepção de docente no Programa Ler e Escrever, a partir de sua expansão em 2008, verificando algumas de suas implicações para o trabalho do professor.

\section{O Programa Ler e Escrever}

O Programa Ler e Escrever é uma política voltada para o desenvolvimento do ensino e aprendizagem das competências orais e escritas pelos alunos do ciclo I do ensino fundamental paulista. Partindo da Resolução n.86/2007 (SÃO PAULO, 2007a, art. $1^{\circ}$ ), seu pressuposto é que os anos iniciais ( $1^{\circ}$ ao $5^{\circ}$ ano) do ensino fundamental, que englobam de forma mais específica o processo de alfabetização, apresentavam falhas e fracassos de longa data. Assim, a justificativa oficial de sua expansão no estado deu-se pela "urgência em solucionar as dificuldades apresentadas pelos alunos de Ciclo I com relação às competências de ler e escrever, expressas nos resultados do SARESP 2005"; bem como pela "necessidade de promover a recuperação da aprendizagem de leitura e escrita dos alunos de todas as séries do Ciclo I" e pela "imprescindibilidade de se investir na efetiva melhoria da qualidade de ensino nos anos iniciais da escolaridade" (SÃO PAULO, 2007a, art. $1^{\circ}$ ).

Para estruturar o Programa, a Resolução n. 86/2007 estabeleceu como suas metas:

I - alfabetizar, até 2010, a todos os alunos com idade de até oito anos do Ensino Fundamental da Rede Estadual de Ensino;

II - recuperar a aprendizagem de leitura e escrita dos alunos de todas as séries do Ciclo I do Ensino Fundamental. (SÃO PAULO, 2007a, art. $1^{\circ}$ ).

Além das metas expostas, o documento “Apresentação do Programa” (SÃO PAULO, 2007b) ressaltou que o Ler e Escrever teria como objetivos principais:

- Apoiar o professor Coordenador em seu papel de formador de professores dentro da escola; 
- Apoiar os professores regentes na complexa ação pedagógica de garantir aprendizagem de leitura e escrita a todos os alunos, até o final da $2^{\mathrm{a}}$ série do Ciclo I / EF;

- Criar condições institucionais adequadas para mudanças em sala de aula, recuperando a dimensão pedagógica da gestão;

- Comprometer as Universidades com o ensino público;

- Possibilitar a futuros profissionais da Educação (estudantes de cursos de Pedagogia e Letras), experiências e conhecimentos necessários sobre a natureza da função docente, no processo de alfabetização de alunos do Ciclo I / EF.

Nessa ótica, foram elencadas diversas ações necessárias para tornar viável o alcance dos objetivos dispostos no documento "Apresentação do Programa” (SÃO PAULO, 2007b, p. 1) e das metas elencadas na Resolução 86 (SÃO PAULO, 2007a, Art. $1^{\circ}$ ). As ações tomadas para cumprimento de tais objetivos e metas não se restringiam à distribuição dos materiais e aplicação desses na rede de ensino paulista, mas envolviam a formação de toda a equipe educacional: o professor atuante no cotidiano do ensino da leitura e escrita, a equipe gestora pertencente às escolas (diretor e coordenador), os supervisores de ensino e os Professores Coordenadores de Núcleo Pedagógicos (PCNPs).

Conforme se nota pelo estudo do Programa (SÃO PAULO, 2007a; SÃO PAULO, 2007b), essa formação se daria em diferentes âmbitos e seria fragmentada em diversos momentos. Os planejamentos desses processos formativos ocorreriam na Coordenadoria de Estudos e Normas Pedagógicas e no Departamento de Orientações técnicas, órgãos vinculados a Secretaria de Educação do Estado de São Paulo. Nessa etapa do planejamento, aconteceria a formação dos PCNPs, profissionais pertencentes à Diretoria de Ensino de cada região, que teriam orientações e instruções para o funcionamento do Programa. Os PCNPs, no interior das Diretorias de Ensino, organizariam processos formativos para os professores coordenadores pertencentes às escolas, a cada quinze dias. O professor coordenador, após receber esses cursos de formação quinzenal, apresentaria o conteúdo nas ATPCs (Aulas de Trabalho Pedagógico Coletivo) e nas reuniões pedagógicas, orientando os professores regentes sobre o trabalho com os materiais disponibilizados pelo Programa e discutiria a solução das dificuldades expostas pelos professores regentes a partir da perspectiva defendida no Programa (TASSONI; MEGID, 2015, p. 198).

Outras ações envolveriam o oferecimento de suporte para a atuação do professor regente. Foi proposto que, nas salas dos anos iniciais do ensino fundamental, principalmente nos primeiros anos, houvesse a presença de um universitário dos cursos de Pedagogia ou Letras 
(SÃO PAULO, 2007b). Essa ação foi desenvolvida pela Secretaria de Estado da Educação com a criação do Programa Bolsa Formação, comumente chamado Bolsa Alfabetização.

O Bolsa Alfabetização foi um programa aliado ao Ler e Escrever, destinado aos alunos de graduação da licenciatura em Letras ou Pedagogia das IES (Instituições de Ensino Superior), que, supervisionados por professores da graduação, recebiam bolsas para exercer atividades de recuperação da aprendizagem nas escolas estaduais paulistas com os professores regentes. Destarte, o Programa Bolsa Alfabetização, segundo o documento de Apresentação (SÃO PAULO, 2007b, p. 3, grifos do original), previa “a atuação de estudantes universitários nas classes de PIC [Projeto Intensivo no Ciclo I] e de $1^{\text {a }}$ série $/ 2^{\circ}$ ano do Ensino Fundamental da rede pública estadual, para auxiliar os professores na alfabetização dos alunos. Chamados alunos pesquisadores", estes seriam "indicados por instituições públicas e privadas de Ensino Superior conveniadas", dentro das áreas previstas (SÃO PAULO, 2007b, p. 3).

O papel dos "alunos pesquisadores" era o de auxiliar os docentes regentes no atendimento e na assistência às crianças que estavam em processo de alfabetização, bem como na organização das aulas de modo que, a partir dessa ação, conforme interpretação oficial, o aluno pesquisador seria a concretização da "existência de um segundo professor em sala de aula" (SÃO PAULO, 2007b, p. 3).

Para estruturação e funcionamento do Programa nas escolas paulistas, houve também o acompanhamento institucional sistemático da Secretaria de Estado da Educação às diretorias de ensino para apoiar o desenvolvimento do trabalho (SÃO PAULO, 2007b, p. 2). Esse acompanhamento se deu por meio dos processos formativos multiplicadores descritos acima a formação dos PCNPs na Coordenadoria de Estudos e Normas Pedagógicas que, posteriormente, no interior das Diretorias de ensino se ocupariam da formação dos professores coordenadores, enquanto tais coordenadores, nas escolas, fariam a formação dos professores regentes - e, das avaliações institucionais, como o SARESP (Sistema de Avaliação de Rendimento Escolar do Estado de São Paulo), que monitorava e acompanhava o desenvolvimento e os resultados das ações tomadas pelo Programa posto à rede de ensino paulista.

É relevante considerar que, para estruturação do Ler e Escrever nas escolas, a Secretaria também realizou a distribuição de materiais para suporte pedagógico do professor, bem como para os próprios alunos. Dentre eles, estavam livros paradidáticos e acervos literários em bibliotecas dispostas em sala de aula, enciclopédias, letras móveis, calculadoras, globos entre outros materiais para auxílio de ensino de leitura e escrita. 
Os livros distribuídos aos alunos pelo Programa, nomeados de Coletânea de Atividades (SÃO PAULO, 2011), eram materiais com propostas de atividades envolvendo sequências didáticas e projetos de leitura e escrita que seriam trabalhados durante todo o ano letivo. Assim, era distribuída uma Coletânea de Atividades para cada ano do $1^{\circ}$ ao $5^{\circ}$ ano do ensino fundamental.

Além desses materiais, o Programa também dispunha dos "Guias do planejamento e orientações didáticas" (SÃO PAULO, 2008b; 2010b; 2014; 2015) para utilização do professor regente. Este Guia deveria servir para o professor alfabetizador como instrumento de detalhamento das atividades cotidianas de sala de aula. Segundo a Carta ao Professor, disposta no início de um dos Guias (SÃO PAULO, 2010b, p. 6-7), "além de ser um canal de comunicação com seu professor coordenador", deveria "servir para apoiar seu planejamento e sua atuação em sala de aula". Isso porque a Secretaria interpretava que o Guia seria "útil em seu planejamento [do professor] e, sobretudo, em suas decisões pedagógicas" (SÃO PAULO, 2010b, p. 6-7, grifos do original), de modo que, como se nota, tais Guias teriam o papel de nortear e, até mesmo, interferir nas práticas educacionais das escolas públicas paulistas.

Muito embora não houvesse nenhum documento evidenciando a abordagem metodológica do Programa, pode-se dizer que esta pautava-se no que a Secretaria de Estado da Educação de São Paulo chamava de construtivismo. Tal afirmação é notada, segundo Constancio (2012), pelas referências dos materiais dispostos, como, por exemplo, os materiais didáticos para alunos e os "guias" para os professores, que se baseavam nos trabalhos de Ana Teberosky e Emília Ferreiro. Ainda, segundo Souza (2015, p. 75), é notável que o Programa alicerçava "sua proposta na concepção construtivista de alfabetização, utilizando a perspectiva do letramento".

Dessa forma, o Estado de São Paulo, ao discursar sobre a melhoria da qualidade do ensino dos anos iniciais ( $1^{\circ}$ ao $5^{\circ}$ ano) do ensino fundamental paulista, criou o Programa Ler e Escrever, enquadrando as práticas docentes em seus objetivos, concepções e procedimentos.

\section{A concepção docente nos documentos do Programa}

Para se identificar a concepção de docente no Ler e Escrever, foi realizada a análise de alguns materiais dispostos no Programa, sendo eles: Orientações curriculares para o Estado de São Paulo: Língua Portuguesa e Matemática (SÃO PAULO, 2008a), Guia de planejamento e orientações didáticas (SÃO PAULO, 2008b; 2010b; 2014; 2015), Expectativas de 
aprendizagem para o primeiro ano do Ensino Fundamental de nove anos (SÃO PAULO, 2009), Cadernos de planejamento e avaliação do professor alfabetizador - 1 série (SÃO PAULO, 2010a), e Orientações didáticas fundamentais sobre as expectativas de aprendizagem de Língua Portuguesa (SÃO PAULO, 2013).

Conforme se nota nos materiais analisados (SÃO PAULO, 2008a; 2008b; 2009; 2010a; 2010b; 2013; 2014; 2015), um dos objetivos deles seria possibilitar que o professor se tornasse competente em sua forma de ensinar. Nas palavras de um dos documentos:

As orientações didáticas que oferecemos aqui facilitarão seu trabalho. São dicas práticas que incluem desde aspectos da organização da sala de aula e dos agrupamentos de alunos, até encaminhamentos didáticos que envolvem suas intervenções, passando por situações didáticas comuns aos projetos, sequências atividades permanentes. E também desenvolvemos detalhadamente as sequências e os projetos, além de sugestões de atividades e modelos que você poderá reproduzir e usar com seus alunos. (SÃO PAULO, 2010b, p. 45, grifos nossos).

Tais destaques na citação, revelam o caráter instrutivo e prescritivo que elas têm frente ao professor, dotando-o de um papel tecnicista na educação (SAVIANI, 1985), ao situa-lo como executor do material do Programa Ler e Escrever. Isso também pode ser percebido em outras afirmações presentes em diferentes documentos do Programa, como: "Vamos detalhar as expectativas relacionadas à aprendizagem da escrita e, assim, apresentar, em linhas gerais, $o$ que deve ser feito em sala de aula" (SÃO PAULO, 2008b, p. 29, grifos nossos); "Siga as orientações até o momento" (SÃO PAULO, 2008b, p. 45, grifos nossos); "Planeje uma aula para explicar algumas das etapas que comporão o projeto e como será a elaboração do projeto final” (SÃO PAULO, 2010b, p. 119, grifos nossos); “Apresentamos a seguir algumas sugestões de listas que podem ser usadas em atividades [...] aproveite-as para desenvolver atividades variadas, seguindo encaminhamentos semelhantes aos propostos aqui" (SÃO PAULO, 2010b, p. 87, grifos nossos).

Segundo o Programa, a prática do planejamento seria uma ação fundamental para o professor tornar-se "um docente bem sucedido", sendo ela muito pontuada nos documentos analisados (SÃO PAULO, 2008a; 2008b; 2009; 2010a, 2010b; 2013; 2014; 2015). Com a justificativa de melhoria da construção do planejamento do professor, foi publicado pelo Programa um Caderno com planilhas das quais o docente deveria usar para se orientar em seu planejamento, bem como, preencher, efetuando o registro de suas atividades em aula. Esse documento intitulava-se Caderno de Planejamento e Avaliação (SÃO PAULO, 2010a). Segundo o referido documento, o professor deveria "registrar seu planejamento semanal, as 
informações sobre seus alunos", bem como registrar suas reflexões e avaliações sobre suas atividades (SÃO PAULO, 2010a, p. 4).

Essas indicações sobre o planejamento, em uma primeira investigação, poderiam ser interpretadas de forma a pensar que o professor, frente ao material, deteria suficiente autonomia sobre seu trabalho, posto que o planejamento do professor "é, e sempre será fruto da sua experiência e das decisões profissionais" (SÃO PAULO, 2008b, p. 52). Todavia, ao se analisar as orientações que se seguem, vê-se explicitada a forma de efetuar o planejamento, o modelo a ser usado, quando usá-lo, entre outras indicações, que sugerem a restrição do trabalho do professor, ao lhe colocar numa situação de subordinação às instruções oficiais, rompendo com a ideia de autonomia que se poderia esperar de suas práticas de ensino diárias e de seu planejamento. Nesse perspectiva, destaca-se os seguintes trechos dos materiais, que revelam que os documentos extrapolam o campo da orientação e acabam indo no sentido da indução de práticas e do controle do trabalho docente: "Na próxima página há outro quadro: trata-se de um modelo para você copiar e preencher de acordo com seu planejamento semanal" (SÃO PAULO, 2010b, p. 42, grifos nossos); “você encontrará uma planilha que deverá ser preenchida com os dados da sondagem, as orientações gerais e o espaço para organizar e registrar o planejamento da sua rotina" (SÃO PAULO, 2008b, p. 44, grifos nossos); “é preciso planejar uma diversidade de situações em que possam, em diferentes momentos, centrar seus esforços ora na aprendizagem do sistema, ora na linguagem que se usa para escrever" (SÃO PAULO, 2008a, p. 6, grifos nossos).

Assim, como se nota, os discursos expostos nos documentos analisados (SÃO PAULO, 2008a; 2008b; 2009; 2010a, 2010b; 2013; 2014; 2015) demonstram que a interpretação oficial sobre os professores estaduais paulistas era a de que estes possuem pouco conhecimento sobre os conteúdos a serem trabalhos com os alunos, restando a eles o papel técnico, ou seja, de "máquina" de aplicar nos alunos um material com método, atividades e conteúdos previamente definidos (SAVIANI, 1985 p. 42) pelo Programa Ler e Escrever. Não por acaso, nos materiais, o professor é constantemente subestimado, como ilustrado nas citações abaixo, que apresentam documentos explicando alguns conteúdos aos docentes:

As notícias costumam ter três partes: título, chamada e desenvolvimento [...]. (SÃO PAULO, 2015, p. 35).

A função do título é sintetizar o conteúdo central, procurando atrair a atenção do leitor; a chamada complementa o título, ressaltando a informação principal; o desenvolvimento expõe a notícia com detalhes [...]. (SÃO PAULO, 2015, p. 35). 
Algumas das palavras assinaladas não aparecem no dicionário na mesma forma em que estão no texto: por exemplo, não há no dicionário a palavra "armações", no plural, mas sim "armação", no singular. No caso dos verbos, é preciso procurá-los por sua forma no infinitivo [...]. (SÃO PAULO, 2010b, p. 111).

As adivinhas ou charadinhas são textos que apresentam um enigma. Utilizam duplos sentidos ou semelhanças entre palavras para dar pistas, pistas estas que às vezes criam mais dificuldades [...]. (SÃO PAULO, 2010a, p. 100).

Essas frases evidenciam como tais materiais subestimam o docente, em sua formação e capacidade de trabalho, ao lhe explicar conteúdos que, de um modo geral, já são de conhecimento inclusive de pessoas não formadas em nível superior. Caminha-se nesse sentido para a intensificação da desvalorização docente, posto que o contrário, segundo lembra Martins (2010, p. 28), demandaria "reconhecer a formação e o trabalho do professor em toda a sua complexidade".

Os documentos ainda estabelecem as expectativas de aprendizagem dos estudantes, que revelam o modelo de aluno, ou melhor, o ideal de aluno que está por trás do Programa e o professor desejável nesse sentido (SÃO PAULO, 2008a; 2008b; 2009; 2010a, 2010b; 2013; 2014; 2015). Conforme os materiais, as crianças devem ser capaz de avançarem "no sentido de se tornarem cidadãs plenas" e o professor é quem possibilita esse avanço, estreitando o contato dessas "com a cultura escrita" (SÃO PAULO, 2010b, p. 18). Os professores devem atuar, portanto, para que os alunos tornem-se "leitores plenos, usuários competentes de leitura e da escrita em diferentes esferas e participantes da cultura escrita", sendo que não se pode considerar "alfabetizado quem sabe apenas o suficiente para assinar o nome e tomar o ônibus" (SÃO PAULO, 2010b, p. 14). Isto é, as crianças devem tornar-se a cada dia mais competentes: "leitores e escritores competentes" (SÃO PAULO, 2008b, p. 17).

Indo mais adiante na análise do material, nota-se que o ideal que se tem dos alunos e dos procedimentos de ensino no Programa - e que devem ser aplicados em sala de aula - é o de um sujeito padrão em seus gostos, interesses e desinteresses, segundo sua faixa etária, sem que se atentem às outras especificidades que existem nesses indivíduos, o que pode ser evidenciado nas seguintes passagens dos materiais: “Também serve para discutir com eles acontecimentos em vários âmbitos, pois geralmente se interessam apenas por esportes e cotidiano [...] (SÃO PAULO, 2015, p. 37, grifos nossos)"; "Nessa faixa etária os alunos demonstram grande interesse pela leitura de contos de mistério, pois estes possibilitam a experimentação de trajetórias emocionantes [...] (SÃO PAULO, 2015, p. 108, grifos nossos)"; "Não é preciso ensinar as crianças a gostar de ouvir histórias, pois isso é natural para elas [...]” (SÃO PAULO, 2014, p. 45, grifos nossos); “[...] é importante que os alunos sejam convidados a dizer o que 
pensaram ou sentiram a partir da história". Assim, no "início, tais comentários são bastante simples, mas com o tempo tendem a ganhar qualidade [...]" (SÃO PAULO, 2014, p. 46, grifos nossos).

Tais afirmações oficias levam ao questionamento de até que ponto é possível a Secretaria fazer tais generalizações sobre os alunos da rede de ensino, tendo em vista a extensão do Estado paulista e a complexidade que é uma criança. Ainda é possível se questionar se seria essa a melhor orientação para os docentes tendo em vista os diferentes contextos e espaços em que estão inseridos. É evidente que as crianças, usualmente, possuem certas características comuns dependendo de sua faixa etária. No entanto, ao distribuírem um material oficial para toda rede de ensino com uma visão restrita sobre a criança, deixa-se de estimular no professor a percepção sobre o que é diferente e peculiar nos sujeitos de sua sala, posto que cada aluno, contexto, cidade, escola, sala de aula etc. tem uma realidade própria que o professor precisa decifrar. Entender isso e lecionar nesses espaços fazem parte das atividades docentes, sendo grandes desafios postos a eles por seus trabalhos.

No que diz respeito à estrutura organizacional dos documentos analisados (SÃO PAULO, 2008a; 2008b; 2009; 2010a, 2010b; 2013; 2014; 2015), a Secretaria aponta para uma mudança no ambiente escolar a partir dos objetivos propostos no Programa. A estrutura dos prédios já construídos é questionada pelos materiais analisados, a partir da seguinte questão: “o que fazer quando há um prédio escolar que não é adequado ao funcionamento de uma proposta que amplie as competências infantis e não as limite?” (SÃO PAULO, 2009, p. 10). A resposta para essa questão, segundo o material, acenaria para ação dos professores. Nas palavras do documento:

Se a equipe tem uma proposta que realmente está bem construída em direção à autonomia e expressão da criança, fazer as adaptações necessárias não é tão difícil. Modificar a organização da sala para incluir, por exemplo, cantos de atividades diversificadas, não é tão difícil quando há boa vontade de todos os envolvidos. Descobrir outros usos para área externa, para refeitórios, enfim, se há uma proposta educativa coesa, bem fundamentada, é possível, mesmo com os prédios existentes, construir novos ambientes. (SÃO PAULO, 2009, p. 10).

Como se percebe, a interpretação oficial é a de que a estrutura dos prédios deveria ser modificada pela ação e boa vontade dos professores e dos envolvidos na educação das crianças. No entanto, ficam as dúvidas: será mesmo que é suficiente apenas a ação e boa vontade dos envolvidos para mudanças tão profundas e complexas no ambiente físico escolar? A Secretaria da Educação não deveria oferecer respaldo, especialmente financeiro, para a política proposta e as mudanças esperadas? Vale lembrar que, muito embora a sabedoria em remodelar espaços 
seja usualmente uma das qualidades docentes frente às adversidade que enfrentam, há locais, ambientes e estruturas físicas nas escolas que precisam de suporte financeiro do poder público para que possam ser adequados para o oferecimento de um ensino que promova a excelência em qualidade.

Ainda, os documentos do Programa (SÃO PAULO, 2008a; 2008b; 2009; 2010a, $2010 b ; 2013 ; 2014 ; 2015)$ evidenciam demasiada ênfase quanto ao uso de seus materiais para colaborar, inclusive, na organização da sala, da escola e do trabalho docente. Por isso, destacam que seria fundamental na organização do trabalho docente o preenchimento das fichas, tabelas, planilhas do material que o ajudariam na reorganização de seu trabalho (SÃO PAULO, 2010a).

Também, vale destacar que, as sequências didáticas apresentadas nos Guias de Planejamento e Orientações Didáticas (SÃO PAULO, 2008b; 2010b; 2014; 2015) supõem as atividades que devem ser trabalhadas no contexto da sala de aula pelos professores, interferindo na organização do espaço e tempo desse local. A título de ilustração dessa afirmação, apresentamos as citações dos documentos analisados abaixo, nas quais se evidenciam tais situações:

As fichas apresentadas a seguir constituem um instrumento útil para ajudar você a analisar as atividades desenvolvidas. Para utilizá-las de fato de modo eficiente, faça um planejamento prévio, guiando-se pelas sugestões de atividades que apresentamos aqui, e procure reunir todos os dados necessários para uma análise completa [...]. (SÃO PAULO, 2010b, p. 24).

O quadro a seguir fornece uma sugestão de organização da rotina semanal. Inclui também o tempo previsto para as outras áreas de conhecimento, bem como para as salas de leitura e de informática [...]. (SÃO PAULO, 2010b, p. 42).

[...] organizamos um quadro orientador em que é apresentado o que uma rotina semanal de leitura e de escrita deve contemplar [...]. (SÃO PAULO, 2008b, p. 37).

Sugerimos que você faça ditados de números: o primeiro no início do ano e o segundo na última semana de junho [...]. (SÃO PAULO, 2010b, p. 35).

Sugerimos que você desenvolva a atividade "Passa problemas": a primeira no início do ano; a segunda, em julho. Você pode organizar os alunos em grupos, mas eles devem resolver individualmente os problemas propostos [...]. (SÃO PAULO, 2010b, p. 36).

Sugerimos que as atividades de produção, interpretação e análise de números sejam realizadas ao menos duas vezes por semana [...]. (SÃO PAULO, 2010b, p. 41).

Ao se analisar a estrutura curricular do Programa presente nos documentos pesquisados (SÃO PAULO, 2008a; 2008b; 2009; 2010a, 2010b; 2013; 2014; 2015), verifica-se que os conteúdos a serem trabalhados pelos docentes, segundo os escritos da Secretaria, "envolvem a ampliação do que os alunos sabem a respeito das convenções sobre a escrita, as letras e seus 
sons", e, ao mesmo tempo "permitem que se dediquem ao conhecimento das práticas sociais de leitura e escrita e dos gêneros vinculados a elas, considerando seus usos reais" (SÃOPAULO, 2010b, p. 85); além disso, "tanto os saberes sobre o sistema de escrita como aqueles sobre a linguagem escrita devem ser ensinados e sistematizados" (SÃO PAULO, 2008b, p. 18). Dessa forma, o currículo que se estabelece nos materiais do Programa prevê a aprendizagem de conteúdos variados que contribuam "para o avanço no conhecimento dos alunos sobre a linguagem escrita e aqueles voltados à reflexão sobre o sistema de escrita" (SÃO PAULO, 2014, p. 32).

Tais conteúdos, conforme os materiais (SÃO PAULO, 2008a; 2008b; 2009; 2010a, 2010b; 2014; 2013; 2015), poderiam ser categorizados em três grandes áreas da língua portuguesa: leitura, escrita e oralidade. Não por acaso, todos os documentos pesquisados se debruçam a orientar os docentes sobre o trabalho pedagógico a ser realizado nessas três áreas.

Algumas expectativas são dispostas sobre como o professor deve se portar frente ao que se espera que os alunos aprendam, de modo que as expectativas de aprendizagem sobre os conteúdos determinados é, segundo um dos documentos (SÃO PAULO, 2015, p. 6, grifos nossos), mais uma ferramenta que objetiva auxiliar o professor "no planejamento de situações didáticas de leitura e escrita, de modo a favorecer um ensino eficaz e uma aprendizagem efetiva de todos os seus alunos". De tal modo, como se percebe, na visão oficial, o professor, ao fazer uso dessas expectativas, supostamente irá efetivar um “ensino eficaz” (SÃO PAULO, 2015, p. 6), ainda que, sob esse formato, segundo Saviani (1991), sua atuação não terá impacto na transformação social. Outra análise feita da documentação é que, embora seja exposto que o professor detém certa autonomia em suas escolhas, inclusive a escolha dos conteúdos, fica induzido que essa escolha se restrinja às opções que lhes são apresentadas pelo material, como mostram os trechos abaixo:

A atividade de leitura em voz alta pelo professor deve ocorrer diariamente com prioridade para textos da esfera literária como contos de fada e populares, mitos [...]. (SÃO PAULO, 2014 p. 33).

Selecione para a roda de jornal um fato que seja foco das atenções no momento - no âmbito dos esportes, da política, da saúde, da ciência [...] Escolha notícias de jornais de diferentes datas e explore com os alunos algumas características desse tipo de texto [...]. (SÃO PAULO, 2015, p. 35).

Diante do exposto, pode-se supor que a escolha mencionada, não se dá no âmbito da escola, mas é configurada e estruturada pela Secretaria de Educação. Isso pode implicar, na prática, que os professores e as escolas sintam-se pressionados por ela. Nesse cenário, é 
consolidada a estrutura curricular da rede de ensino paulista, mais especificamente do Programa Ler e Escrever, e uma determinação do que se deve ensinar, com uma expectativa homogeneizante dos alunos, sem ao menos se ter a dimensão de qual é o contexto e a comunidade a que se ensina.

\section{Considerações finais}

A análise da documentação do Programa Ler e Escrever revela que, com os materiais utilizados pelo Programa, a Secretaria acaba oferecendo aos docentes as "regras do jogo" educacional, indicando as supostas estratégias para se atingir a eficiência previamente estabelecida por ela. Assim, como preleciona Saviani (1985, p. 42), nesse contexto, o professor pode "ser substituído, indiferentemente, sem prejuízo do processo, por qualquer outro professor, ou, até mesmo pela máquina: a máquina de ensinar”.

Assim, pela análise dos documentos do Programa Ler e Escrever (SÃO PAULO, 2008a; 2008b; 2009; 2010a, 2010b; 2013; 2014; 2015), evidencia-se que, para se alcançar “experiências de sucessos” (SÃO PAULO, 2015, p. 7), segundo a visão oficial, bastaria, supostamente, os professores que lecionam na rede de ensino paulista usufruírem dos materiais que lhes são dispostos. Todavia, um questionamento importante que pode ser extraído dessa constatação é: será que esses materiais facilitam o trabalho do professor ou facilitam o controle sobre o trabalho docente? Por conseguinte, pelos resultados sinalizados neste artigo, é possível se chegar a hipótese de que o Programa parece estar servindo mais para o controle do trabalho do professor, até porque os materiais que o compõem parecem querer interferir inclusive na escola, já que, além de agirem sobre as ações docentes, apresentam forte tendência em ditar como deve ser organizado o espaço e o currículo escolar. Com isso, pode-se estar diluindo na escola a preocupação com a diversidade de alunos e dos contextos, já que tudo parece estar passando pela lente padronizada da Secretaria da Educação.

À vista disso, elucida-se que o trabalho docente no material do Programa Ler e Escrever é subestimado e reduzido a aplicação de instruções e orientações em sala de aula. Neste caso, como se nota, é o material que se torna o centro do processo educacional, e o professor, ao que tudo indica, parece estar se tornando um coadjuvante frente a "um material didático em moldes de um Receituário” (CONSTANCIO, 2012, p. 39), que fragiliza sua prática ao destituíla de espaço para a fundamentação e teorização do conhecimento (SAVIANI, 1991). 
Não por acaso, os materiais analisados apresentam as orientações em forma de instruções, que demonstram essa ação da Secretaria. Constancio (2012, p. 42) aponta que os materiais apresentam muitos detalhes, em especial os Guias, sendo que o conteúdo existente, os textos, "são instrucionais, oferecem apenas orientações de como o professor deve aplicar as atividades, realizar as avaliações e até mesmo as intervenções possíveis que ele deve realizar com os alunos". Com isso, a sala de aula e a escola têm seus espaços e tempos enfatizados nos documentos analisados (SÃO PAULO, 2008a; 2008b; 2009; 2010a, 2010b; 2013; 2014; 2015): os materiais definem como deve ser organizado os espaços, a rotina do professor, instruí como o docente deve preencher suas planilhas e organizar seus alunos. Sob essa ótica, as escolas paulistas, na lente das determinações oficiais, parecem ser vistas como iguais, como se cada comunidade não apresentasse suas particularidades e como se os docentes paulistas não fossem capazes de organizar seus trabalhos, suas salas e seus alunos para atenderem suas particularidades.

Assim, como explica Souza (2015, p. 77), o Programa Ler e Escrever propõe um ensino que já vem pronto, no qual o professor é interpretado como "um mero executor do que o governo quer que se ensine", objetivando "melhorar o desempenho nas avaliações externas, gerando o processo de intensificação e auto intensificação do trabalho docente". Por isso, conforme Brandão e Trevilin (2017. 176), o professor, no Programa, "não precisa planejar sua aula”, pois ela “já está pronta, é só seguir o manual”, já que, como interpreta Constancio (2012, p. 18), "a inserção e obrigatoriedade do uso dos materiais didáticos do Programa Ler e Escrever [...] controla e manipula os professores e os torna mero instrumento de trabalho". Com isso, para Brandão e Trevelin (2017, p. 186), o Programa atua na "desvalorização do profissional a partir do momento em que a formação se limita apenas a seguir as prescrições previamente determinadas pelo programa", já que, conforme David e Lourencetti (2015, p. 61), os professores não participam da elaboração das aulas e da escolha dos conteúdos indicados oficialmente a serem ministrados em aula.

Como se viu pela análise dos documentos, o trabalho docente não é o único com pretensão de padronização pelo Programa, mas também há uma expectativa de aluno, de escola, de currículo, como se fossem esses, elementos que pudessem ser postos em caixas e moldes, para mais facilmente se controlar o processo educacional. Destarte, como interpreta Souza (2015), os materiais apontam para uma mudança de paradigma no ensino paulista. Não obstante, lembra, se o objetivo do material é realizar uma mudança de paradigma de ensino paulista, conforme Souza (2015), haveria que se considerar que isso exige "o envolvimento de todas as 
pessoas que fazem parte do processo de educação, acontecendo mudanças significativas na estrutura geral de toda educação" (SOUZA, 2015, p. 73).

Por isso, conforme pesquisa realizada por Zoccal (2011 p. 120), embora exista todo um aparato pedagógico colocado aos docentes pelo Programa Ler e Escrever, há que se considerar que, no cotidiano, os professores, em alguns momentos, "submetem-se; em outros, resistem; em outros, hesitam ou tentam reproduzir a proposta do Programa Ler e Escrever sem ter consciência para a justificativa de seu procedimento" (ZOCCAL, 2011, p. 119). Apesar dos impactos do Programa sobre o trabalho docente e dos desejos oficiais quanto à escola paulista, há que se lembrar que a realidade e seus docentes são muito maiores.

\section{REFERÊNCIAS}

BRANDÃO, Carlos da Fonseca; TREVELIN, Fátima Gil de Oliveira. O "Programa Ler e escrever" no contexto de uma escola municipal. RPGE- Revista online de Política e Gestão Educacional, v. 21 n. 1, p. 167-189, jan./abr. 2017. Disponível em: < https://periodicos.fclar.unesp.br/rpge/article/view/9990/6597 > Acesso em: 03 dez. 2018.

CONSTANCIO, Alexandra Regina. A padronização do trabalho docente: crítica Programa Ler e Escrever. 2012. 130 f. Dissertação (Mestrado em Educação) - Pontifícia Universidade Católica de São Paulo, Educação, São Paulo, 2012.

DAVID, Alessandra; LOURENCETTI, Gisela do Carmo. A supervisão de ensino no programa Ler e Escrever da SEE/SP: análise de termos de visita. In: Encontro Nacional de Educação - EDUCERE, Seminário Internacional de Representações Sociais, Subjetividade e Educação - SIRSSE, Seminário Internacional sobre Profissionalização Docente SIPD/Cátedra UNESCO; Encontro Nacional sobre Atendimento. 7, 3, 5, 9. 2015, Curitiba, Anais... Curitiba: Educere, 2015, v. 1. p. 30508-30521. Disponível em < http://educere.bruc.com.br/arquivo/pdf2015/19345_11603.pdf > Acesso em: 11 dez. 2018.

DUARTE, Newton. Educação escolar, teoria do cotidiano e a escola de Vigotski. 4 ed. Campinas: Autores Associados, 2007.

MARTINS, Lígia Márcia. O legado do século XX para a formação de professores. In. MARTINS, Lígia Márcia; DUARTE, Newton (orgs.). Formação de professores: limites contemporâneos e alternativas necessárias. São Paulo: Cultura Acadêmica, 2010, p. 13-31.

RAMOS, Géssica Priscila. O professor na política educacional: tentativa de identidades forjadas? Revista Brasileira de Política e Administração da Educação, v. 28, p. 129/7-143, 2012. Disponível em: <https://seer.ufrgs.br/rbpae/article/viewFile/36146/23334>. Acesso em: 28 fev. 2018.

RAMOS, Géssica Priscila. A política educacional paulista (1995-2010) e seus impactos nas identidade da escola e do professor. Revista Brasileira de Política e Administração da 
Educação, v. 29, p. 537-556, 2013. Disponível em: <https://seer.ufrgs.br/rbpae/article/view/47224> . Acesso em: 28 fev. 2019.

SAVIANI, Dermeval. Filosofia da educação brasileira. Org. Dermeval Saviani et al: coordenação de Durmeval Trigueiro Mendes. $2^{a}$ ed. - Rio de Janeiro, Civilização Brasileira: 1985.

SAVIANI, Dermeval. Escola e democracia. $8^{a}$ ed. - São Paulo, Cortez/Autores Associados, 1985.

SAVIANI, Dermeval. Pedagogia histórico crítica: Primeiras aproximações. $2^{\mathrm{a}}$ ed. - São Paulo: Cortez/Autores Associados, 1991.

SÃO PAULO (MUNICÍPIO) Secretaria da Educação. PORTARIA 6.328/05 - SME de 26- 9-2005. Institui, para o ano de 2006, o Programa "Ler e escrever - prioridade na Escola Municipal", nas Escolas Municipais de Ensino Fundamental - EMEFs e Escolas Municipais de Ensino Fundamental e Médio - EMEFMs. São Paulo, 2005. Disponível em: < http://www3.prefeitura.sp.gov.br/cadlem/secretarias/negocios_juridicos/cadlem/integra.a sp?alt=27092005P\%20063282005SME> Acesso em: 30 out. 2018.

SÃO PAULO (ESTADO). Secretaria de Educação. Resolução SE - 86, de 19-12-2007. Institui, para o ano de 2008, o Programa "Ler e Escrever", no Ciclo I das Escolas Estaduais de Ensino Fundamental das Diretorias de Ensino da Coordenadoria de Ensino da Região Metropolitana Grande São Paulo. São Paulo, 2007a. Disponível em: < http://siau.edunet.sp.gov.br/ItemLise/arquivos/86_07.HTM?Time=10/3/2012\%2012 >. Acesso em: 14 dez. 2018.

SÃO PAULO. (ESTADO) Secretaria da Educação. Fundação para o Desenvolvimento da Educação (FDE). Programa Ler e Escrever. Apresentação. São Paulo: FDE, 2007b. Disponível: $<$ http://lereescrever.fde.sp.gov.br/Handler/UplConteudo.ashx?jkasdkasdk=184\&O $\underline{\mathrm{T}=\mathrm{O}}>$ Acesso em: $10 \mathrm{dez} .2018$.

SÃO PAULO (ESTADO). Secretaria da Educação. Orientações Curriculares do Estado de São Paulo: Língua Portuguesa e Matemática - Ciclo I / Secretaria da Educação, Coordenação, Neide Nogueira, Telma Weisz; Elaboração, Angela Maria da Silva Figueiredo e outros- São Paulo: FDE, 2008a.

SÃO PAULO (ESTADO). Secretaria da Educação. Ler e escrever: guia de planejamento e orientações didáticas; professor alfabetizador - 1a série / Secretaria da Educação, Fundação para o Desenvolvimento da Educação; adaptação do material original, Claudia Rosenberg Aratangy, Rosalinda Soares Ribeiro de Vasconcelos. - São Paulo : FDE, 2008 b.

SÃO PAULO (ESTADO). Secretaria de Educação Básica. Resolução SE 96, de 23-122008. Estende o Programa "Ler e Escrever" para as Escolas Estaduais de Ensino Fundamental do Interior. São Paulo, 2008c. Disponível em: <http://www.educacao.sp.gov.br/lise/sislegis/detresol.asp?strAto=200812230096 $>$. Acesso em: 23 mar. 2018.

SÃO PAULO (ESTADO) Secretaria da Educação. Expectativas de aprendizagem para o $1^{\circ}$ ano do Ensino Fundamental de nove anos. Secretaria da Educação, Fundação para o 
Desenvolvimento da Educação; organização, Claudia Rosenberg Aratangy. São Paulo: FDE, 2009.

SÃO PAULO (ESTADO) Secretaria da Educação. Ler e escrever: caderno de planejamento e avaliação - professor alfabetizador - 1 a série / Secretaria da Educação, Fundação para o Desenvolvimento da Educação; organização, Claudia Rosenberg Aratangy. 3. ed. São Paulo: FDE, 2010a.

SÃO PAULO (ESTADO) Secretaria da Educação. Ler e escrever: guia de planejamento e orientações didáticas; professor $-\mathbf{3}^{\mathbf{a}}$ série / Secretaria da Educação, Fundação para o Desenvolvimento da Educação; adaptação do material original, Marisa Garcia, Milou Sequerra. 2.ed. São Paulo: FDE, 2010 b.

SÃO PAULO (ESTADO) Secretaria da Educação. Ler e escrever: coletânea de atividades $\mathbf{1}^{\circ}$ ano / Secretaria da Educação, Fundação para o Desenvolvimento da Educação; concepção e elaboração, Claudia Rosenberg Aratangy; Milou Sequeira; Marisa Garcia. - São Paulo : FDE, 2011.

SÃO PAULO (ESTADO) Secretaria da Educação. Orientações didáticas fundamentais sobre as expectativas de aprendizagem de Língua Portuguesa / Secretaria da Educação, Coordenadoria de Gestão da Educação básica; elaboração: Kátia Lomba Bräkling; colaboração: Formadoras do Programa Ler e Escrever e Equipe CEFAI; supervisão: Telma Weisz. São Paulo, SEE: 2013.

SÃO PAULO (ESTADO) Secretaria da Educação. Ler e escrever: guia de planejamento e orientações didáticas; professor alfabetizador $-\mathbf{1}^{\mathbf{0}}$ ano / Secretaria da Educação, Fundação para o Desenvolvimento da Educação; coordenação, elaboração e revisão dos materiais, Sonia de Gouveia Jorge... [ e outros]; concepção e elaboração, Claudia Rosenberg Aratangy...[e outros]. - 4. ed. rev. e atual. - São Paulo: FDE, 2014.

SÃO PAULO (ESTADO) Secretaria da Educação. Ler e escrever: guia de planejamento e orientações didáticas; professor $-4^{\circ}$ ano / Secretaria da Educação, Fundação para o Desenvolvimento da Educação. - 7. ed. rev. e atual. São Paulo: FDE, 2015.

SOUZA, Tatiana Palamini. O trabalho docente e os programas de formação continuada para professores alfabetizadores 2015. 105 f. Dissertação (mestrado) - Universidade Metodista de Piracicaba, Educação, 2015.

TASSONI, Elvira Cristina Martins; MEGID, Maria Auxiliadora Bueno Andrade. A formação de professores alfabetizadores e o programa Ler e escrever. ETD - Educ. Temat. Digit. Campinas, SP, v. 17 n. 1 p. 193-210 jan./abr. 2015.

VILLALOBOS, Isabel. Análise da fundamentação dos materiais didáticos do Programa Ler e Escrever da Prefeitura de São Paulo/ SP. 2014. 267 f. Tese (Doutorado em educação). Programa de Pós-Graduação em Educação. Faculdade de Educação da Universidade de São Paulo. São Paulo, 2014.

ZOCCAL, Sirlei Ivo Leite. A relação dos professores alfabetizadores com o saber no contexto do "Programa Ler e Escrever". 2011. 189 f. Dissertação (Mestrado) Universidade Católica de Santos, Programa de Mestrado em Educação, Santos: 2011. 


\section{SOBRE AS AUTORAS:}

\section{Letícia Lais da Silva}

Mestranda em Educação pela Universidade Federal de São Carlo (UFSCar). Membro do Grupo de Pesquisa UFSCar: Sociologia, Trabalho e Educação. E-mail:

leticia_lays@hotmail.com

(iD http://orcid.org/0000-0002-8734-963X

\section{Géssica Priscila Ramos}

Doutora em Educação pela Universidade Federal de São Carlo (UFSCar). Docente do Programa de Pós-Graduação em Educação da UFSCar. Membro do Grupo de Pesquisa UFSCar: Sociologia, Trabalho e Educação. E-mail: gessicaramos@ufscar.br

(iD http://orcid.org/0000-0002-1254-4510 